\title{
Smart Grid and its future perspectives in Australia
}

\author{
Ahmed M.A. Haidar*, Kashem Muttaqi, Danny Sutanto \\ Australian Power Quality and Reliability Centre, School of Electrical, Computer and Telecommunications Engineering, University of Wollongong, NSW,
} Australia

\section{A R T I C L E I N F O}

\section{Article history:}

Received 15 November 2013

Received in revised form

15 May 2015

Accepted 8 July 2015

Available online 30 July 2015

Keywords:

Smart Grid

Smart city

Renewable energy sources

Power grid

Smart meter

\begin{abstract}
A B S T R A C T
The Smart Grid (SG) is an emerging concept, which is in a testing phase in many countries. It is a relatively new perception that integrates electricity and communication on power system networks, which enable SG applications, mainly for the use of Renewable Energy Sources (RES). This paper presents a review of the existing studies on SG systems, the use of SG technologies and the modeling techniques for SG available in the literature. Furthermore, the paper focuses on SG features when connected at a distribution grid and its active distribution management capability. It also identifies the current practice as provided in technical standards and potential industry investments that can facilitate a pathway towards SG development in Australia. The paper also has highlighted the possible areas of research that would be required to implement practical SG facilities.
\end{abstract}

(c) 2015 Elsevier Ltd. All rights reserved.

\section{Contents}

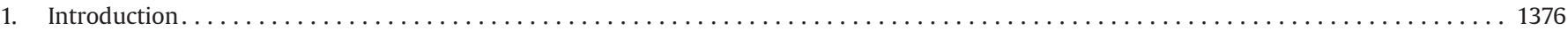

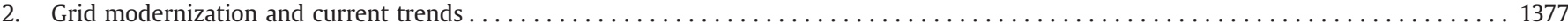

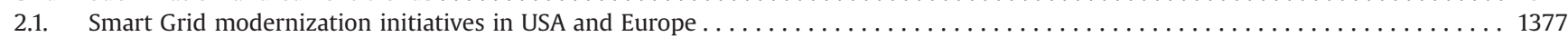

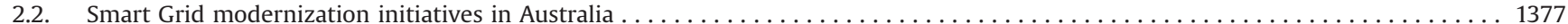

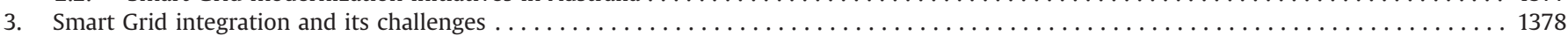

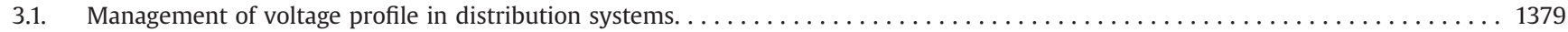

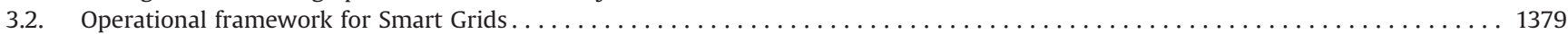

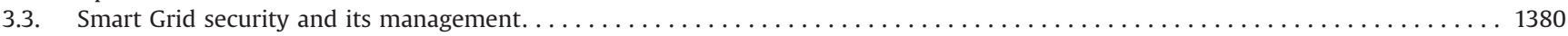

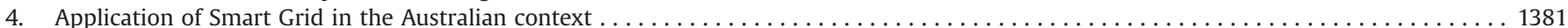

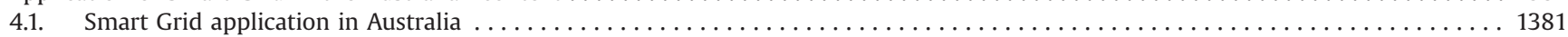

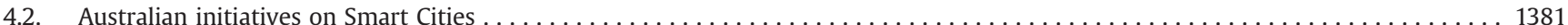

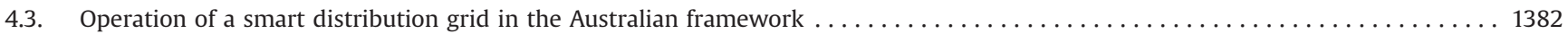

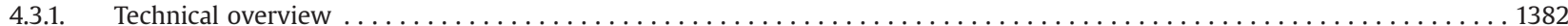

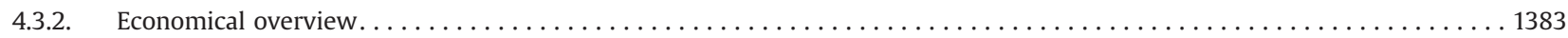

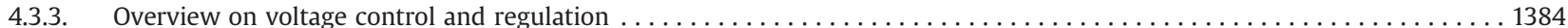

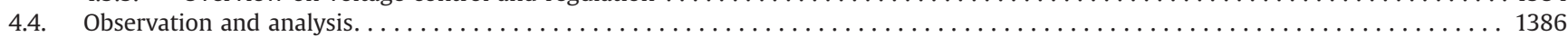

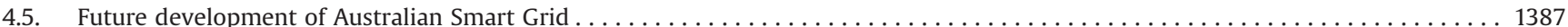

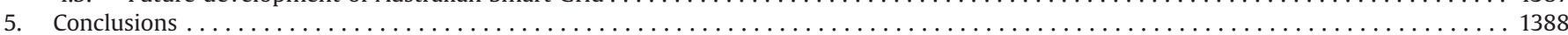

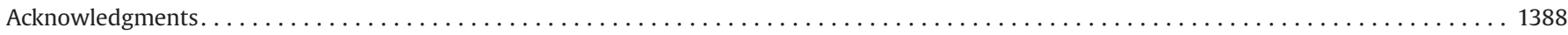

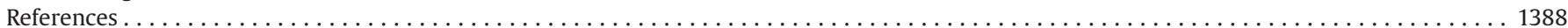

\footnotetext{
* Corresponding author. Tel.: +612 42213520.

E-mail address: ahaidar@uow.edu.au (A.M.A. Haidar).
} 